\title{
GIS Exploitation for New Facility Location Decisions- A Logistics Perspective
}

\author{
Afzal Mohammad Khaled*, Yong Jin Kim**
}

\begin{abstract}
Logistical facility location decisions can make a crucial difference in the success or failure of a company. Geographical Information Systems (GIS) have recently become a very popular decision support system to help deal with facility location problems. However, until recently, GIS methodologies have not been fully embraced as a way to deal with new facility location problems in business logistics. This research makes a framework for categorizing empirical facility location problems based on the intensity of the involvement of GIS methodologies in decision making. This framework was built by analyzing facility location models and GIS methodologies. The research results revealed the depth of the embracement of GIS methodologies in logistics for determining new facility location decisions. In the new facility location decisions, spatial data inputs are almost always coupled with the visualization of the problems and solutions. However, the usage of GIS capability solely (i.e. suitability analysis) for problem solving has not been embraced at the same level. In most cases, the suitability analysis is used together with special optimization models for choosing among the multiple alternatives.
\end{abstract}

Keywords: logistics, facility location, GIS usages level

Submisson Date : 05/03/2011 Revision Date : 03/19/2012 Acceptance Date : 03/19/2012

* Ph.D Student, Graduate School of Logistics, Inha University, Korea

E-mail:khaled_afzal@yahoo.co.kr

** Corresponding author, Professor, Asia-Pacific School of Logistics, Inha University, Korea

E-mail: youngjin@inha.ac.kr 


\section{Introduction}

Logistics is a value emitting cost function related to the flow and storage of goods, services and information of business processes. A Firm can gain a competitive advantage by increasing its logistics service value per cost ratio. As a result, logistics problems such as facility location decisions, network decisions, transportation decisions, inventory decisions, logistics planning and forecasting decisions etc. were relentlessly tried to being solved by improved methodologies. The solutions for these logistics problems have evolved in three ways- Optimal operations, breakthrough technological inventions and automated decision support. Mathematical models are formulated for optimal decision making in supply chain designs, location, transportation, inventory and materials management, collaborative planning, forecasting and replenishment etc. Breakthrough technologies were invented to assist with real time communication and operations (e.g. Global Positioning Systems, Radio Frequency Identification, Electronic Data Interchanges, automated distribution centers, computer based tracing and tracking systems etc.). Lastly some high-end integrated software like SAP's Enterprise Resource Planning (ERP), i2, etc. has been developed for collective and automated decision support systems.

Most of the optimization decisions have been made by using mathematical models with simplified assumptions regarding the spatial attributes. The choice of location is one of such decisions that can make a crucial difference between failure and success (Stortmann, 2000). One fabulous way to incorporate spatial information into location decision making is by using the Geographic Information System (GIS). GIS can screen out poor and infeasible sites in a logical manner (Church, 2002) and thereby reduce decision alternatives. However, the limited functionality of GIS has impeded its use in empirical analysis in the past. These days, the increased capacity and computational power of computers, as well as the developing data depository and commercially available GIS software (e.g. ArcInfo, TransCAD etc.) make it possible to evaluate some logistical location decisions by using geographical references.

The application of GIS in business decision making began getting empirical attention in 1990. However, until recently an evaluation of how effective GIS methodologies are when used for solving new facility location decision problems in logistics had not been performed. Our objective in this paper is to reveal the current level and effectiveness of GIS usage when evaluating new facility location decision problems.

The null hypothesis here is that, all kinds of new facility decision locations fairly embrace all available GIS tools / methodologies. The scope of the analysis was limited to new facility location decisions in only the logistics field in order to keep it manageable. 
Literature was reviewed in order to build a representative set of location models and levels of GIS functionality. A framework from these two representative sets was then used in order to categorize the published application papers on new facility location decisions in logistics. Electronic searches conducted on renowned and relevant databases were also utilized in order to gather the application papers. The search was limited from 1990 to 2010 since the embracement of using GIS in the business field did not gain significant interest until after 1990. The keywords used in the search were: GIS, facility Location, Logistics, and site selection. The list from the search database is also given in the appendix. After the categorization of the applied papers from the frame work mentioned above, the percentage of usage for each type of GIS tool that was used to evaluate each type of location problem gave us valuable insight into the level of involvement of GIS in new facility location decisions in logistics.

The rest of the paper is organized as follows. In Section 2, different kinds of facility location problems/ models are defined. Section 3 discusses GIS from the viewpoint of gradual increment of spatial methodologies. The framework and analysis results were presented in Section 4. Lastly, section 5 wraps up with a discussion and provides a summary of our key ideas and concludes with our final thoughts.

\section{Logistics Facility Location Models}

Facility location problems are often created by the lack of spatial resources which creates the allocation problems. In order to be successful, management must investigate where to physically locate a set of facilities (resources). The components of the problem are a spatially distributed set of demand points (customers), a candidate set of facility locations whose selection (numbers in some cases) are to be determined, and a pay off matrix which denotes all alternative relationships between demand points and prospective facility points. The objective is to locate the facility set in such a way that the total payoff involved is optimized within the given constraints (it could be minimization or maximization depending upon the special problem). There are two basic questions which must be answered. The first question is where to locate the facility or which candidate to select? The second question is - which location will serve which demand point? We must determine if the allocation problem is related to multiple facility decisions or if a single change will be effective. A slightly outdated but very good and complete taxonomy of location problems was given by Brandeau and Chiu (1989).

The following paragraph briefly reviews the basis classifications of location models. 
Hale and Moberg (2003) classified location problems into three broad objective categoriesmedian (minisum or maxisum), center ( minimax or maximin) and covering problems (set covering and maximal covering). The solution approaches were classified into three basic surfaces: continuous space, discrete spaces, and network spaces. Klose and Drexl (2005) classified the location models based on their shape/ topography/space, objectives, capacity constraints, number of stage, number of products, demand elasticity, static or dynamic, uncertainty and combined models (e.g. location-routing model). Revelle and Eiselt (2005) mentioned two types of surfaces - d-dimensional real space and network surface, both of which were further subdivided into continuous or discrete location problems. Based on their objective, they classified location problems as pull objective problems (desirable location problems), push objectives (undesirable location problems) and equity (balancing) objective problems. Minisum median problems, Minimax center problems and covering problems all fall under pull objective problems. Whereas maxisum and maximin location problems all fall under push objectives. Some constraints of those problems were mentioned as uncertainty and capacity constraints. Revelle, Eiselt and Daskin (2008) categorized location modeling into four categories: Analytic (simplified), continuous, network and discrete location models. They also summarized contemporary discrete location literature and categorized it into median, center and covering problems. Eiselt (2008) in an initiative to identify the Canadian contribution which had been made in the field of location analysis mentioned seven types of location models. These are: minisum problems, minimax problems, undesirable facilities models, probabilistic location models, hierarchical location models, competitive location models, location-routing problems and location models with equity objectives. Melo, Nickel and Saldanha-da-Gama (2009) reviewed many facility location papers from the supply chain perspective. They categorized relevant researches under a framework which considered the number of stages (location layers), the number of periods and the amount of uncertainty. They also tried to incorporate capacity, inventory, procurement, production, routing, transportation mode, multi-periods, relocation, financial aspects and risk management etc. with location decisions. Josep-Maria Arauzo-Carod et al. (2010) used a unique approach for classifying empirical studies for industrial locations in order to find determinants of industrial locations. He also divided all location analysis into either Discrete Choice models or Count Data models. In discrete choice models both the decision maker and/or candidate locations related factors affect the location decision. Whereas, in count data models the territories related to the data are the determinants for reducing the alternatives. The location model categories which were mentioned in the reviews are elaborately given in the appendix. 


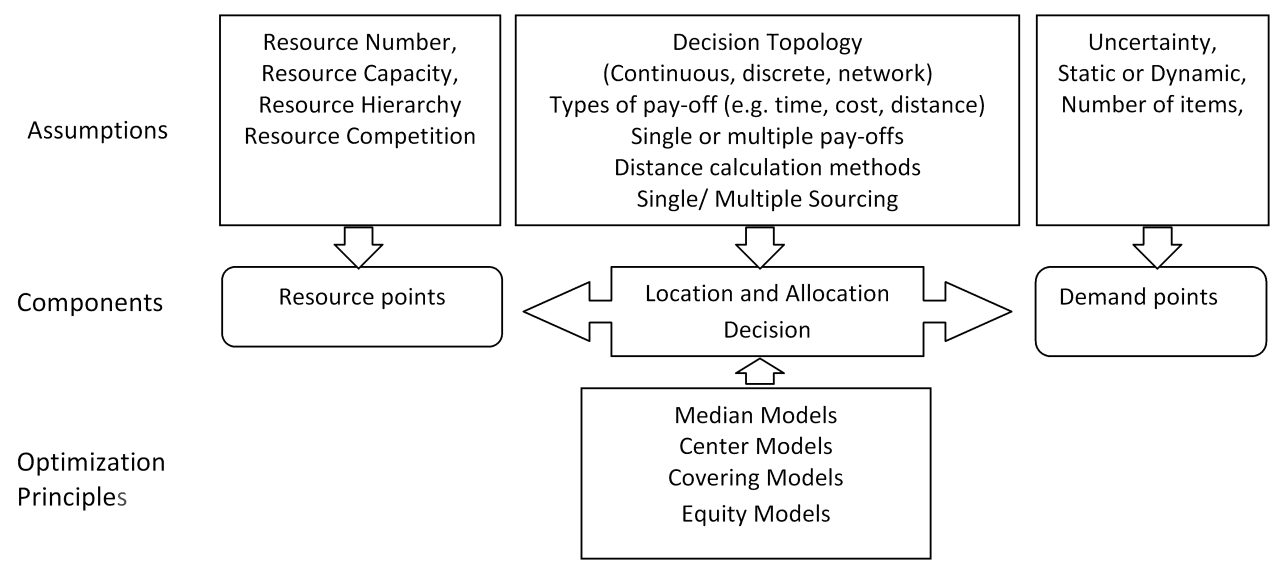

Figure 1.

New facility location models

For our intended framework, we present new facility location models in Figure 1. The new facility location models are composed of four mutually exclusive optimization principles which try to determine the location and allocation of the resource points in order to serve some specified demand points assuming some of the stated conditions regarding the facilities, demand and decision space. These optimization principles/objective based models and some of their popular extensions are analyzed below. Farahani et al. (2009), Drezner and Hamacher (2004), Daskin (1995) are the best sources for further investigating these basic location models.

\subsection{Basic Models : The Median / Minisum models}

Try to minimize the demand weighted total distance between the demand nodes and the facilities which are allocated corresponding to those nodes. Median models are typically useful when cost-based or profit based objectives are considered. However, when customer service takes priority over profit, the Center/ gravity/ Minimax models gets the main focus. Center models try to locate $\mathrm{p}$ facilities which minimize the maximum distance that separates any demand node from its nearest facility. However, whenever there is a predefined service standard, the center/ gravity models may appear without a solution because the distance may fall outside of the service standards. The models used for such cases are location set coverage models and maximal coverage location models. The location set coverage model tries to find the endogenous minimum number of facility locations which will cover $100 \%$ of the demand points within the specified service standards. 
However, because of the limited budget when 100\% coverage becomes impossible, it is also important to cover the points with greater demand which is addressed by the maximal coverage location models. Equity Models or balancing objectives also attempt to locate the facilities in order to provide some degree of equal treatment to all customers. Instead of trying to achieve global optimization, the equity model tries to ensure fairness to all customers. For further analysis of this type of model, a review of the work from Erkut (1993), Marsh and Schilling (1994) and Eiselt and Laporte (1995) is recommendable.

\subsection{Some Extensions of location models}

Undesirable or obnoxious facility models come with additional objectives. Examples can be choosing a location for a nuclear power plant or a prison. These models hold exactly the opposite objectives of median or center models. However, since all undesirable facilities also possess some desirable features, there are also some maximum pushing limits for these models. We refer to Erkut and Neuman (1989), Daskin (1995) and Eiselt and Sandblom (2004) for further research on these kinds of models. The competitive model was founded by Hotelling (1929) and Von Stackelberg (1934). The facility site decisions are made in order to optimize the market share for existing competitor(s), or to help anticipate future competition (Hakimi, 1983; RevVelle, 1986, Mirchandani and Francis,1990; Drezner, 1994,1995; Serra and ReVelle, 1995; Miller et al., 1996; Plastria, 2001; ReVelle and Eiselt, 2005; Eiselt, 2008). Serra and Revelle (1994) formalized a model to preempt the possible market share for future site decisions which will be made by competitors. The hierarchic model includes multi-level facilities with homogeneous functions in each level. The problem is comparing alternative facilities at different and matching levels so that the functions related to service quality can be maximized. In order to further analyze these model types, we referred to Klose and Drexl (2005). Hub location models emerged in order to evaluate economies of scale and higher frequencies. There are often variation and median problems in a network space where the origins and destinations are connected by spokes to the nearest hubs. Economy of scale is achieved through either increased volume transfer between the hubs or through consolidation at the hub centers. Higher frequency is achieved at the expense of transfer costs at the hubs. The work of O,Kelly $(1986,1987)$, Campbell et al. (1994a, 2001), Klincewicz (1996), and Aykin (1994) are highly recommended for further study on this model. The location-routing model incorporates location-allocation problems and routing problems into a single model. An in-depth discussion on combined location-routing models can be found in Perl and Daskin (1985), Bouliane and Laporte (1992), Aykin (1995a) and Klose (2001). 


\section{Geographic Information System Methodologies}

The United States Geological Survey defines GIS as a computer system capable of assembling, storing, manipulating, and displaying geographically referenced information. According to NASA, "GIS is an integrated system of computer hardware, software, and trained personnel which links topographic, demographic, utility, facility, image and other resource data that is geographically referenced."

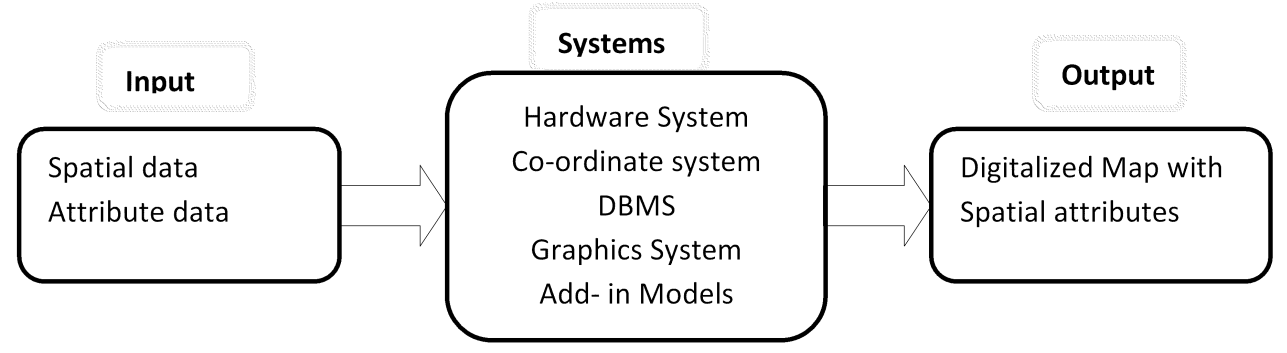

Figure 2.

GIS operating system

There is currently some well known GIS software commercially available for practical use. Some of them are ArcGIS and Arc logistics from ESRI, by Caliper Corporation, GeoMedia from Intergraph, MapInfo Professional from MapInfo Corp and GeoConcept from GeoConcept SA etc.

GIS contains two types of data models: Raster and Vector based data models. It acquires spatial data, then stores and manages it in either the raster or vector format. For specific analysis, it manipulates the raster and vector data through conversion, aggregation, overlay and interpolation. Some of its analysis tools are spatial query, buffer, topological autocorrelation, centrality, proximity etc. It also allows hypothesis testing by using statistical models which are called spatial statistical analysis. The spatial analysis function of GIS allows for the detection of hidden spatial patterns which are used to build models for the purpose of predicting spatial outcomes. Alan T. Murray (2010) mentioned five components/tools of GIS that support geographical decision making. These components are: the acquisition component, the management component, the manipulation component, the analysis component and the display component. By using these components, GIS methodologies have contributed to location science in terms of data input, visualization, problem solution and theoretical advances. For our classification framework we will first 
use three of the GIS contribution levels. The contribution levels are arranged in terms of the depth of involvement of GIS during the decision making process.

\subsection{Spatial data input}

GIS supports location science by unveiling spatial inputs that allow improved location models. So, at the minimum level, GIS provides the capacity to access spatial information. When identifying topological relationships, GIS spatial search methodology becomes an effective solution. Spatial data inputs tend to store three components of data: space (where), time (when), and object (what). Accordingly, several kinds of queries (Andrienko et al., 2003) are possible, these queries are:

- When + where à what: Describe the objects or set of objects that are present at a given location or set of locations at a given time or set of times.

- When + what àwhere: Describe the location or set of locations occupied by a given object or set of objects at a given time or set of times.

- Where + what àwhen: Describe the times or set of times that a given object or set of objects occupied a given location or set of locations.

This methodology is often used for verification of model data and error propagation.

\subsection{Visualization}

The most popular utilization of GIS in empirical location problems is the visualization of the decision. Visualization provides a better understanding of the objectives, decisions and model space. There are lots of examples in the literature where GIS has been used solely for display purposes. Some examples of visualization are the voronoi diagram for representing trade area, the spider diagram which is used to represent location and allocation decisions simultaneously, the 3D presentation of routes and topography etc. Visualization not only helps us to understand and support the decision making process, but it also indicates whether such decisions make sense in reality. 


\subsection{Problem solution}

More rigorous versions of the GIS application are used for problem solution. If the possible facilities are small in number or a single site, then the location problem can solely be solved through the use of GIS tools. This type of analysis is called suitability analysis. Some of the GIS tools which can be used for suitability analysis are overlay, proximity, buffer and centrality. However, if the number of feasible solutions is numerous, then the inclusion of an optimization model (post-suitability analysis) for choosing the best site (sites) among the alternatives becomes necessary. Some commercial GIS packages such as ArcGIS, TranCad and MapInfo come with such decision models as add-Ins. Beyond this, it is also possible to write one's own model within a commercial GIS package by using supported programming languages such as .NET, C++, COM or Visual Basic.

\section{Application of GIS methodologies for logistics facility location decisions}

In this section we will classify the new facility location related application literature which uses GIS methodologies in all stages of the solution process.

\subsection{Classification framework}

We developed the classification framework by using the basic and extended facility location models which were discussed in section 2 and the GIS methodologies which were mentioned in Section 3. The facility location models chosen for the framework were the median model, center model, covering model, equity model, undesirable location model, competitive model, hierarchic model, hub location model and location-routing model. The levels of utilization for the GIS methodologies were measured by their contribution to the facility location decisions. The levels with significant contributions were spatial data input, visualization, suitability analysis, and add-Ins models / programming in an ascending order. Empirical papers which used multiple facility location models were accounted for in all respected groups of models. Logistics facility location decisions are based on ranked demographic data and visualized and solved solely by GIS suitability analysis. They are also separately categorized from other location analysis models since they do not belong to any of the conventional model categories which are mentioned here. Research gets accounted for in the fourth level (add-in models/ programming) of GIS methodologies only when a script is made by using a GIS platform such as $\mathrm{C}++$, visual basic, etc. No counting 
was allowed during the fourth level of the GIS methodological use because optimization techniques outside of the GIS platform i.e. GIS solution was used separately for further calculations by different mathematical methods. The crude classification table of empirical literature is displayed in the appendix.

\section{Table 1.}

Numerical results of GIS embracement

\begin{tabular}{|l|c|c|c|c|c|}
\hline \multirow{2}{*}{ Facility Location models } & \multirow{2}{*}{$\begin{array}{c}\text { Number of } \\
\text { literatures }\end{array}$} & $\begin{array}{c}\text { Spatial } \\
\text { data input }\end{array}$ & Visualization & $\begin{array}{c}\text { Suitability } \\
\text { Analysis }\end{array}$ & $\begin{array}{c}\text { Add-in models } \\
\text { / programming) }\end{array}$ \\
\hline Median models & 9 & 9 & 8 & 5 & 3 \\
\hline Center models & 5 & 5 & 5 & 3 & 1 \\
\hline Coverage models & 4 & 4 & 3 & 4 & 1 \\
\hline Equity models & & & & & \\
\hline Undesirable location model & 1 & 1 & 1 & 1 & \\
\hline Competitive model & 3 & 3 & 3 & 2 & 1 \\
\hline Hierarchic model & 2 & 2 & 2 & 1 & 1 \\
\hline Hub model & 1 & 1 & 1 & 1 & 2 \\
\hline Location-routing model & 5 & 5 & 4 & 2 & \\
\hline Others & 3 & 3 & 3 & 3 & \\
\hline Total & $32^{*}$ & 33 & 30 & 22 & \\
\hline
\end{tabular}

* One literature dealt with more than one model

\subsection{Numerical results and analysis}

The pattern of data shows that the embracement of GIS methodology is skewed to the left. This indicates that GIS usage in location decision making is still gradually improving. Most of the empirical studies which attempted to use GIS involved spatial data input $(100 \%)$ and visualization (91\%) tools for GIS. A fair amount (67\%) of them used spatial suitability analysis which is the key strength of GIS. Few studies used embedded add-in software or scripting within the GIS platform (27\%). No studies on equity location models were found which used GIS. Few or very few studies on undesirable facility location models (3\%), hierarchic models $(6 \%)$ and hub models $(3 \%)$ used GIS tools for problem solving and illustrations. 


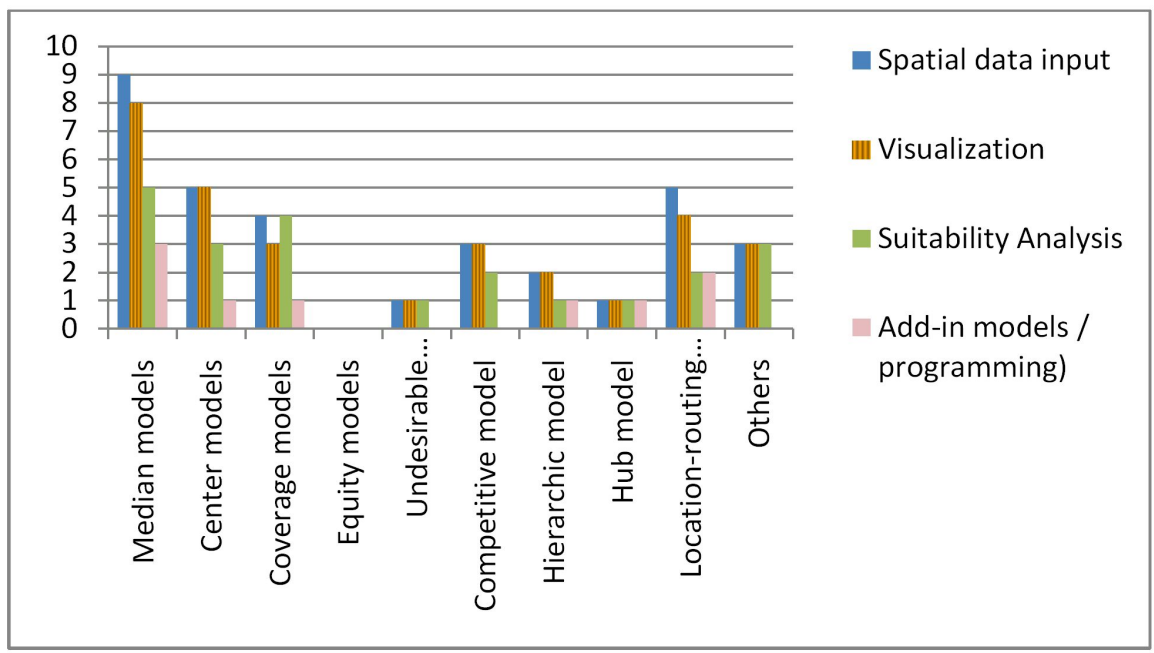

Figure 3.

GIS methodology utilization level by Location model

The key GIS strength - its spatial suitability analysis was mostly used for median models, center \& coverage models and user attraction models which are covered under others categories. This research provides a great deal of important information. First, the total usage of GIS methodologies for new facility logistic location analysis is very low. During a 20 year duration from 1990 to 2010 the electronic database mentioned in the Appendix revealed only 33 empirical studies which truly embraced GIS for actual solution analysis purposes. This means that there are still a large number of empirical studies being conducted which are not tapping into the primary strength of GIS. Secondly, those who used GIS methodologies did not utilize its full potential. GIS was primarily used as a data input tool and/or results visualization tool. The preference of researchers to use other mathematical tools cannot be ignored. These findings are surprising because it is now possible to incorporate most of these other models within GIS. However, such attempts to do so are not very common and the usage of add-in models and scripting accounts currently stands at only $27 \%$. Therefore, we definitely believe that the full potential of the GIS methodology is still waiting to be tapped. 


\section{Conclusion}

Logistical functions are diverse in nature, but almost $80 \%$ of their functions are related to geographic cordinates. Some are also related to other types of spatial analysis such as the optimum usage of vehicle space for loading etc. Since one of the strongest attributes of GIS is spatial query, a lot of logistical problems can be optimized through the use of GIS. Literature is being developed both in the field of theoritical (including hypothetical, simulated) data related logitics optimization processes and in the practical implementation of GIS in the logistics field for the purpose of creating better solutions. The contribution of this paper is a framework made out of systematically classified facility location models and GIS methodologies. The classification of empirical literature on new facility location decisions is based on the depth of the embracement of GIS methodologies within the solution approach which was also conducted. As expected, the level of embracement gradually reduces from spatial data input to the use of the special optimization model within the GIS platform. When dealing with new facility location issues, decision spatial data inputs are almost always coupled with the visualization of the problem and its possible solutions. However, the usage of GIS capability solely (i.e. suitability analysis) for problem solving has not been embraced at the same level. Even though GIS is capable of incorporating standalone mathematical models within its platform, we were able to locate very few initiatives were this had been done. Further research is required in order to identify the key issues which are currently hindering GIS usage in logistics with regards to new facility location decisions. Other issues related to the integration of mathematical models into the GIS platform should also be analyzed in a detailed manner. This research discussed the GIS embracement level in new facility location decisions in logistics. Similar studies of GIS usage in other logistical fields may help in identifying the sectors where GIS possesses ample opportunities. Since visualization is easier to comprehend and spatial solutions posses an advantage over non-spatial solutions, GIS will definitely dominate in solving spatial problems in the near future.

\section{Acknowledgements}

This work was partially supported by INHA UNIVERSITY Research Grant and the National Research Foundation of Korea Grant funded by The Korean Government (NRF-2011-413-B00008). 


\section{References}

Andrienko, N., Andrienko, G., and Gatalsky P(2003) Exploratory spatio-temporal visualization: an analytical review. Jounal of Visual Languages and Computing, 14.

ArauzoCarod, J. M., Liviano-Solis, D., and Manjon-Antolin, M(2010). EMPIRICAL STUDIES IN INDUSTRIAL LOCATION: AN ASSESSMENT OF THEIR METHODS AND RESULTS. Journal of Regional Science 50.3 : 685. Print.

Aykin, T(1994) Lagrangian relaxation based approaches to capacitated hub-and-spoke network design problem. European Journal of Operational Research 79, :501523.

Aykin, T(1995a)The hub location and routing problem. European Journal of Operational Research 83,: 200-219.

Bergqvist, Rickard, and Jonas Tornberg(2008) Evaluating Locations for Intermodal Transport Terminals. Transportation Planning and Technology. August : 465.

Bouliane, J.and Laporte, G(1992). Locating postal relay boxes using a set covering algorithm. American Journal of Mathematical and Management Sciences 12, : 65-74.

Brandeau, M. L. and Chiu S.S(1989) An Overview of Representative Problems in Location Research. Management science 35.6 : 645. Print.

Camm, J.D., Chorman, T.E., Dill, F.A., Evans, J.R., Sweeney, D.J. and Wegryn, G.W (1997) Blending OR/MS, judgment, and GIS: restructuring P and G's supply chain. Interfaces, $27: 128-142$

Campbell, J.F(1994a) Integer programming formulations of discrete hub location problems. European Journal of Operational Research 72, :387-405.

Campbell, J.F., Labelle, A. and Lagevin, A(2001) A hybrid travel distance approximation for a GIS-based decision support system.(2001) Journal of Business Logistics, $22.2,: 165-182$.

Cannon, Kimberly(2007). Market Analysis: Using GIS to Analyze Areas For Business Retail Expansion. Volume 9. Papers in Resource Analysis. 8pp. Saint Mary's University of Minnesota University Central Services Press. Winona, MN

Celli, G., et al(2008)Optimal Location of Biogas and Biomass Generation Plants. Universities Power Engineering Conference, UPEC 2008. 43rd International. 2008. 1-6. Print.

Cheng, E(2007) A GIS Approach to Shopping Mall Location Selection. Building and Environment 42.2 : 884-92. Print.

Church, Richard L(2002) Geographical Information Systems and Location Science. Computers \& Operations Research 29.6 : 541-62. Print. 
Dah-Ming Shiah, Chin-Tun Hung, and Shu-Wen Chen(2009). Multi-Capacities Ambulance Location Model. Testbeds and Research Infrastructures for the Development of Networks \& Communities and Workshops, TridentCom 2009. 5th International Conference on. 2009. 1-6. Print.

Daskin Mark S. Network and Discrete location, Wiley-interscience series, New York,

Drezner, T(1994) Locating a single new facility among existing, unequally attractive facilities. J Reg Sci 34:237-252

Drezner, T. and Hamacher H. W(2004). Facility location-Application and Theory, Springer -Verlag, Berlin,

Eiselt, H. A(2008). Location Science in Canada. Information systems and operational research 46.4: 283. Print.

Eiselt, H. A. and Laporte, G(1995) Objectives in location problems, in Drezner, Z. (ed.): Facility Location: A Survey of Applications and Methods, Springer-Verlag, New York, pp. 151-180

Eiselt, H. A. and Sandblom, C-L(2004). Decision Analysis, Location Models, and Scheduling Problems, Springer-Verlag, Berlin-Heidelberg-New York

Erkut, E(1993) Inequality measures for location problems, Location Science, 1, p. 199-217

Erkut, E. and Neuman, S(1989). Analytical models for locating undesirable facilities, European Journal of Operational Research, 40: 275-291.

Farahani, Reza Z. and Hekmatfar M(2009). Facility Location, Springer Company, New York

Hakimi, S.L(1983). Locating new facilities in a competitive environment. Eur J Oper Res, $12: 29-35$

Hale, T. S. and Moberg C.R(2003). Location Science Research: A Review. Annals of operations research 123.1: 21. Print.

Heng Li, H., Yu, Ling, and Cheng, E(2005). A GIS-based site selection system for real estate projects. Construction Innovation: Information, Process, Management, 5. $4,: 231-241$

Hill, Rebecca Lee, and Kevin M. Curtin(2011). Solar Powered Light Emitting Diode Distribution in Developing Countries: An Assessment of Potential Distribution Sites in Rural Cambodia using Network Analyses. Socio-economic planning sciences 45.1 : 48-57. Print.

Holl, Adelheid(2004). Manufacturing Location and Impacts of Road Transport Infrastructure: Empirical Evidence from Spain. Regional Science and Urban Economics 34.3 : 341-63. Print. 
Horner, M.W. and Grubesic, T. H(2001). A GIS-Based Planning Approach to Locating Urban Rail Terminals. Transportation 28.1 Print.

Hotelling, H(1929). Stability in competition, The Economic Journal, 39: 41-57.

Khaili, S. M. S. A., A. Ahmad, and A. M. Samad(2010). Optimal Location of Property in United Arab Emirates using Geographical Information System. Signal Processing and Its Applications (CSPA), 2010 6th International Colloquium on. 1-5. Print.

Klincewicz, J.G(1996). A dual algorithm for the uncapacitated hub location problem. Location Science 4, : 173-184.

Klincewicz, J.G(1991). Heuristics for the p-hub location problem. European Journal of Operational Research, 53, 25-37

Klose, A(2001). Standortplanung in distributiven Systemen. Physica, Heidelberg .

Klose, Andreas, and Andreas Drexl(2005). Facility Location Models for Distribution System Design. European Journal of Operational Research 162.1 : 4-29. Print.

Limbourg, S., and B. Jourquin (2009). Optimal Rail-Road Container Terminal Locations on the European Network. Transportation Research Part E: Logistics and Transportation Review 45.4: 551-63. Print.

Lin, W. M., M. T. Tsay, and S. W. Wu(1993). Load Assignment for Determining Substation Service Areas with the Aid of Digital Mapping. TENCON '93. Proceedings. Computer, Communication, Control and Power Engineering.1993 IEEE Region 10 Conference on. 430-434 vol.5. Print.

Ma Jun, et al(2009) Study on Location-Selection of Logistics Distribution Center Based on GIS and Weighted Steiner Tree. Computer Science-Technology and Applications, 2009. IFCSTA '09. International Forum on. 326-329. Print.

Marsh, M. T. and Schilling, D. A(1994). Equity measurement in facility location analysis: a review and framework, European Journal of Operational Research, 74: 1-17

Melo, M. T., S. Nickel, and F. Saldanha-da-Gama(2009). Facility Location and Supply Chain Management - A Review. European Journal of Operational Research 196.2 : 401-12. Print.

Miliotis, P., Dimopoulou, M. , and Giannikos, I(2002). A hierarchical location model for locating bank branches in a competitive environment. Int. Transactions in Operational Research, 9, : 549-565

Miller, H.J(1996). GIS and geometric representation in facility location problems. Int $J$ Geogr Inf Syst 10:791-816

Ming Xie, et al(2007). IFAO-Simo: A Spatial-Simulation Based Facility Network Optimization Framework. Simulation Conference, 2007 Winter. 2221-2226. Print. 
Mirchandani PB, and Francis RL (eds), Discrete Location Theory. Wiley, New York 1990 Murray, A. T(2010). Advances in Location Modeling: GIS Linkages and Contributions. Journal of Geographical Systems : 1. Print.

Noon, C. E., and C. T. Hankins(2001). Spatial Data Visualization in Healthcare: Supporting a Facility Location Decision Via GIS-Based Market Analysis. System Sciences, 2001. Proceedings of the 34th Annual Hawaii International Conference on. 10 pp. Print.

O'Kelly, M(1987) A quadratic integer program for the location of interacting hub facilities. European Journal of Operational Research, 32 : 393-404.

O'Kelly, M(1986). The location of interacting hub facilities. Transportation Science, 20, : 92-106.

Pan Wenan(2009). Research of Demarcating Location of Logistic Center Based on DSS of GIS, wcse, vol. 4, pp.487-491, World Congress on Software Engineering,

Panichelli, Luis, and Edgard Gnansounou(2008). GIS-Based Approach for Defining Bioenergy Facilities Location: A Case Study in Northern Spain Based on Marginal Delivery Costs and Resources Competition between Facilities. Biomass and Bioenergy 32.4: 289-300. Print.

Pearson, Jesse(2007). A Comparative Business Site-Location Feasibility Analysis using Geographic Information Systems and the Gravity Model. Volume 9, Papers in Resource Analysis. 10 pp. Saint Mary's University of Minnesota Central Services Press. Winona, MN

Perl, J. and Daskin, M(1985). A warehouse location-routing problem. Transportation Research B-Methods $19: 381-396$.

Pizzolato, Nelio D., Fabricio Broseghini Barcelos, and Luiz Antonio Nogueira Lorena (2004). School Location Methodology in Urban Areas of Developing Countries. International Transactions in Operational Research 11.6 : 667-81. Print.

Plastria, F(2001). Static Competitive Facility Location: An Overview of Optimisation Approaches. European Journal of Operational Research 129, p 461-470.

Pochampally, K. K., and S. M. Gupta(2004). A Business-Mapping Approach to MultiCriteria Group Selection of Collection Centers and Recovery Facilities. Electronics and the Environment, 2004. Conference Record. 2004 IEEE International Symposium on. 249-254. Print.

Qiming Tian, et al(2009). Decision Support Services for Retail Site Location using a Two-Stage Guiding Optimization Approach. Service Operations, Logistics and Informatics, 2009. SOLI '09. IEEE/INFORMS International Conference on. 487-492. Print. 
ReVelle, C(1986). The maximum capture or sphere of influence location problem hotellin grevisited on a network. J Reg Sci $26: 343-358$

ReVelle, C. S., H. A. Eiselt, and M. S. Daskin(2008). A Bibliography for some Fundamental Problem Categories in Discrete Location Science. European Journal of Operational Research 184.3: 817-48. Print.

ReVelle, C.S. and Eiselt, H.A(2005). Location analysis: a synthesis and survey. Eur J Oper Res $165 \mathrm{p}: 1-19$

Ringo, Linder G(2009). Utilizing GIS-Based Site Selection Analysis for Potential Customer Segmentation and Location Suitability Modeling to Determine a Suitable Location to Establish a Dunn Bros Coffee Franchise in the Twin Cities Metro, Minnesota, Volume 11. Papers in Resource Analysis. 11 pp. Saint Mary's University of Minnesota University Central Services Press. Winona, MN

Serra, D. and ReVelle, C(1994). Market capture by two competitors: the preemptive location problem. J RegSci, 34, p:549-561

Strotmann, Harald(2007). Entrepreneurial Survival, Small Business Economics, 28, 87-104

Vlachopoulou, M., Silleos, G., and Manthou, V(2001). Geographic information systems in warehouse site selection decisions. Int J. Production Economics, 71 : 205-212

Von Stackelberg, H. Freiherr(1934), Marktform und Gleichgewicht (Market and quilibrium), Vienna.

Weigel, D. and Cao, B(1999). Applying GIS and OR techniques to solve Sears techniciandispatching and home -delivery problems. Interfaces, 29 : 112-130.

Wen-Hsiang Lai, and Kei-Zhang Hung(2010). Optimizing New Chain Retail Store Area by usingVoronoi Diagram Technique. Technology Management for Global Economic Growth (PICMET), 2010 Proceedings of PICMET '10: 1-10. Print.

Wu, H. C., C. S. Tsai, and C. N. Lu(1999). Load Forecast in a Competitive Retail Market. Transmission and Distribution Conference, 1999 IEEE. 160-164 vol.1. Print.

Yanping Liang, Xing Qiang Zhang, and Qi Sun(2008). Study on Logistics Distribution Center Location Based on GIS Environment. Service Operations and Logistics, and Informatics, 2008. IEEE/SOLI 2008. IEEE International Conference on. 3007-3010 begin_of_the_skype_highlighting

Zeng, Weiping, M. John Hodgson, and Ignacio Castillo(2009). The Pickup Problem: Consumers' Locational Preferences in Flow Interception. Geographical Analysis 41.1: 107-26. Print.

Zhao, Y. W., et al. GIS-Based Optimization for the Locations of Sewage Treatment Plants and Sewage Outfalls - A Case Study of Nansha District in Guangzhou City, China. Communications in Nonlinear Science and Numerical Simulation 14.4 (2009): 1746-57. Print. 


\section{Appendix:}

Table 1

List of web data bases used for searching literatures

$\begin{array}{ll}\text { Meta Search Engine (Index) } & \text { E-Journal search engine } \\ \text { EBSCO (Academic Source Premier) } & \text { IEEE Xplore } \\ \text { EBSCO (Business Source Premier) } & \text { Springerlink } \\ \text { ERIC (EBSCO) } & \text { WorldCat } \\ \text { Ingentaconnet } & \text { Cambridge Journals Online } \\ \text { Jestor Business } & \text { Emerald } \\ \text { Science Direct } & \text { Oxford Journals } \\ \text { Web of Science } & \text { Taylor \& Francis } \\ \text { SCOPUS } & \text { SAGE } \\ \text { Scirus } & \\ \text { Willey Interscience } & \text { Thesis sites } \\ & \text { ProQuest } \\ & \text { (http://proquest.umi.com) }\end{array}$

Table 2.

Reviewed types of location problems

\begin{tabular}{|c|c|c|c|}
\hline Review papers & $\begin{array}{l}\text { Decision } \\
\text { Surface } \\
\end{array}$ & Objectives & Discussed types of location Problems \\
\hline $\begin{array}{l}\text { Hale and } \\
\text { Moberg } \\
(2003)\end{array}$ & $\begin{array}{l}\text { Continuous } \\
\text { Discrete } \\
\text { Network }\end{array}$ & $\begin{array}{l}\text { Median } \\
\text { Center } \\
\text { Covering }\end{array}$ & $\begin{array}{l}\text { Median : Single/P-median, Conditional } \\
\text { P-median, Dynamic P-median, Aggregation } \\
\text { problem } \\
\text { Center : Single/Multi facility, Rectilinear/ } \\
\text { Euclidian distance } \\
\text { Covering : Set covering problem, Maximal } \\
\text { covering problem Others : Multi period } \\
\text { location allocation models, Intermediate facility } \\
\text { models, Capacitated / un-capacitated model, } \\
\text { Hub location problem, Combined location and } \\
\text { TSP problems }\end{array}$ \\
\hline $\begin{array}{l}\text { Klsoe and } \\
\text { Drexl (2005) }\end{array}$ & $\begin{array}{l}\text { Continuous } \\
\text { Network } \\
\text { Discrete }\end{array}$ & $\begin{array}{l}\text { Minisum } \\
\text { Minimax }\end{array}$ & $\begin{array}{l}\text { Capacity constraints, Single/multi stage } \\
\text { models, Single/ Multiple product models, } \\
\text { Elastic/inelastic Demand models, Static or } \\
\text { Dynamic models, Deterministic/ Probabilistic } \\
\text { models, Combined location-routing models }\end{array}$ \\
\hline
\end{tabular}




\begin{tabular}{|c|c|c|c|}
\hline Review papers & $\begin{array}{l}\text { Decision } \\
\text { Surface }\end{array}$ & Objectives & Discussed types of location Problems \\
\hline $\begin{array}{l}\text { Revelle and } \\
\text { Eiselt (2005) }\end{array}$ & $\begin{array}{l}\text { d-dimensional } \\
\text { real space } \\
\text { Network }\end{array}$ & $\begin{array}{l}\text { Pull (median, } \\
\text { center, } \\
\text { covering) } \\
\text { Push } \\
\text { (obnoxious) } \\
\text { Balancing } \\
\text { objectives }\end{array}$ & $\begin{array}{l}\text { Uncertainty, Capacity constraints, Undesirable } \\
\text { facility problem, Hierarchical sitting, Hub } \\
\text { location , Competitive location, Combined } \\
\text { siting and routing problem, Flow capturing } \\
\text { problem }\end{array}$ \\
\hline $\begin{array}{l}\text { Revelle, et al. } \\
(2008)\end{array}$ & $\begin{array}{l}\text { Analytic, } \\
\text { continuous, } \\
\text { network and } \\
\text { discrete } \\
\text { location models } \\
\end{array}$ & & $\begin{array}{l}\text { Median and Plant location problems Center } \\
\text { and Covering problems }\end{array}$ \\
\hline Eiselt (2008) & $\begin{array}{l}\text { Continuous } \\
\text { Plane } \\
\text { Network }\end{array}$ & $\begin{array}{l}\text { Minisum } \\
\text { Problem } \\
\text { Mnimax } \\
\text { Problem } \\
\text { Undesirable } \\
\text { facility } \\
\text { problem } \\
\text { Equity model } \\
\end{array}$ & $\begin{array}{l}\text { Probabilistic location models } \\
\text { Hierarchical location models } \\
\text { Competitive location models } \\
\text { Location-routing Problem }\end{array}$ \\
\hline $\begin{array}{l}\text { Melo et al. } \\
(2009)\end{array}$ & & & $\begin{array}{l}\text { Single/multi layers facility models, } \\
\text { Single/multi of periods models, } \\
\text { Deterministic/stochastic parameter models, } \\
\text { Single/ multi-commodity models, Capacitated/ } \\
\text { uncapacitated models, Combined models with } \\
\text { capacity, inventory, procurement, production, } \\
\text { routing, transportation mode, relocation, } \\
\text { financial aspect and risk management etc }\end{array}$ \\
\hline $\begin{array}{l}\text { Arauzo-Carod } \\
\text { et al. }(2010)\end{array}$ & & & $\begin{array}{l}\text { Discrete Choice Models, } \\
\text { Count Data Models }\end{array}$ \\
\hline
\end{tabular}


Table Appendix 3.

Application Papers Classification framework

\begin{tabular}{|c|c|c|c|c|c|}
\hline \multicolumn{6}{|c|}{ GIS Methodologies } \\
\hline & New facility location in logistics literatures & $\begin{array}{l}\text { Spatial } \\
\text { data input }\end{array}$ & \begin{tabular}{|l|} 
Visua \\
lizati \\
on \\
\end{tabular} & \begin{tabular}{|l|} 
Suitabili \\
ty \\
Analysis \\
\end{tabular} & $\begin{array}{l}\text { Add-in models } \\
/ \\
\text { programming } \\
\end{array}$ \\
\hline \multirow{9}{*}{ Median models } & Holl (2004) & $\sqrt{ }$ & & & \\
\hline & Panichelli \& Gnansounou (2008) & $\sqrt{ }$ & $\sqrt{ }$ & $\sqrt{ }$ & $\sqrt{ }$ \\
\hline & Yanping et al. (2008) & $\sqrt{ }$ & $\sqrt{ }$ & $\sqrt{ }$ & $\sqrt{ }$ \\
\hline & Limbourg S. And Jourquin B.(2009) & $\sqrt{ }$ & $\sqrt{ }$ & & \\
\hline & Qiming Tian, et al.(2009) & $\sqrt{ }$ & $\sqrt{ }$ & & \\
\hline & Ma Jun et al. (2009) & $\sqrt{ }$ & $\sqrt{ }$ & $\sqrt{ }$ & \\
\hline & Khaili S.M.S.A.(2010) & $\sqrt{ }$ & $\sqrt{ }$ & $\sqrt{ }$ & \\
\hline & Pizzolato et al. (2004) & $\sqrt{ }$ & $\sqrt{ }$ & $\sqrt{ }$ & \\
\hline & Vlachopoulou et al. (2001) & $\sqrt{ }$ & $\sqrt{ }$ & & $\sqrt{ }$ \\
\hline \multirow{6}{*}{ Center models } & Noon and Hankins (2001) & $\sqrt{ }$ & $\sqrt{ }$ & $\sqrt{ }$ & \\
\hline & Pochampally and Gupta (2004) & $\sqrt{ }$ & $\sqrt{ }$ & & \\
\hline & Horner and Grubesic (2001) & $\sqrt{ }$ & $\sqrt{ }$ & $\sqrt{ }$ & \\
\hline & Ming Xie et al. (2007) & $\sqrt{ }$ & $\sqrt{ }$ & & \\
\hline & Heng li and Ling Yu (2005) & $\sqrt{ }$ & $\sqrt{ }$ & $\sqrt{ }$ & $\sqrt{ }$ \\
\hline & Cannon K.M (2007) & $\sqrt{ }$ & $\sqrt{ }$ & $\sqrt{ }$ & \\
\hline \multirow{3}{*}{$\begin{array}{l}\text { Coverage } \\
\text { models }\end{array}$} & Miliotis et al. (2002) & $\sqrt{ }$ & $\sqrt{ }$ & $\sqrt{ }$ & $\sqrt{ }$ \\
\hline & Dah-Ming, Shaih et al (2008) & $\sqrt{ }$ & $\sqrt{ }$ & $\sqrt{ }$ & \\
\hline & Cheng Eddie W.L. et al. (2007) & $\sqrt{ }$ & & $\sqrt{ }$ & \\
\hline \multicolumn{6}{|c|}{\begin{tabular}{|l|l|} 
Equity models & \\
\end{tabular}} \\
\hline $\begin{array}{l}\text { Undesirable } \\
\text { location } \\
\text { model }\end{array}$ & Zhao et al. (2009) & $\sqrt{ }$ & $\sqrt{ }$ & $\sqrt{ }$ & \\
\hline \multirow{3}{*}{$\begin{array}{l}\text { Competitive } \\
\text { model }\end{array}$} & Qiming Tian, et al. (2009) & $\sqrt{ }$ & $\sqrt{ }$ & & \\
\hline & Pearson Jesse K. (2007) & $\sqrt{ }$ & $\sqrt{ }$ & $\sqrt{ }$ & \\
\hline & Wen.H. Lai and Hung (2010) & $\sqrt{ }$ & $\sqrt{ }$ & $\sqrt{ }$ & \\
\hline \multirow{2}{*}{$\begin{array}{l}\text { Hierarchic } \\
\text { model }\end{array}$} & Pan Wen'an (2009) & $\sqrt{ }$ & $\sqrt{ }$ & $\sqrt{ }$ & $\sqrt{ }$ \\
\hline & Camm et al. (1997) & $\sqrt{ }$ & $\sqrt{ }$ & & \\
\hline Hub model & Bergqvist and Tornberg (2008) & $\sqrt{ }$ & $\sqrt{ }$ & $\sqrt{ }$ & $\sqrt{ }$ \\
\hline \multirow{5}{*}{$\begin{array}{l}\text { Location-routin } \\
\text { g model }\end{array}$} & Weigel and Cao (1999) & $\sqrt{ }$ & $\sqrt{ }$ & & \\
\hline & Wu H.C. et al (1999) & $\sqrt{ }$ & $\sqrt{ }$ & & \\
\hline & Lin W.M et al. ( 1993) & $\sqrt{ }$ & $\sqrt{ }$ & & \\
\hline & Zeng W. et al (2009) & $\sqrt{ }$ & $\sqrt{ }$ & $\sqrt{ }$ & $\sqrt{ }$ \\
\hline & Campbell et al(2001) & $\sqrt{ }$ & & $\sqrt{ }$ & $\sqrt{ }$ \\
\hline \multirow{3}{*}{ Others } & Hill and Curtin (2011) & $\sqrt{ }$ & $\sqrt{ }$ & $\sqrt{ }$ & \\
\hline & Ringo Linder G. (2009) & $\sqrt{ }$ & $\sqrt{ }$ & $\sqrt{ }$ & \\
\hline & Celli G. et al (2008) & $\sqrt{ }$ & $\sqrt{ }$ & $\sqrt{ }$ & \\
\hline
\end{tabular}

